\title{
RISK FACTORS ASSOCIATION WITH MRSA NASAL COLONIZATION AMONG PREOPERATIVE PATIENTS IN AZADI TEACHING HOSPITAL-DUHOK, KURDISTAN REGION, IRAQ
}

\author{
Warveen L. Abdulkareem ${ }^{a}$, Nawfal R. Hussein ${ }^{b}$, Ayad A. Mohammed ${ }^{c}$, Sardar H. Arif ${ }^{c}$, Ibrahim A. Naqid ${ }^{b} *$ \\ a Azadi Teaching hospital, Duhok Province, Kurdistan Region - Iraq \\ ${ }^{\mathrm{b}}$ Dept. of Biomedical Sciences, College of Medicine, University of Zakho - Kurdistan, Iraq (ibrahim.naqid@uoz.edu.krd) \\ ${ }^{c}$ Dept. of Surgery, College of Medicine, University of Duhok-Kurdistan, Iraq.
}

\begin{abstract}
:
Background: Nasal colonization with Methicillin-resistant Staphylococcus aureus (MRSA) can predispose to subsequent infections in surgical and non-surgical patients, making the management challenging with increased rates of morbidity, mortality and cost burden.

Objectives: The present study was carried out to evaluate the risk factors of MRSA nasal colonization in preoperative patients in Azadi Teaching Hospital in Duhok Province - Kurdistan Region-Iraq.

Methods: Nasal swabs were obtained from 150 patients after completing a questionnaire. Conventional laboratory methods were carried out to identify Staphylococcus aureus (S. aureus) and antimicrobial susceptibility test was conducted for recognizing MRSA isolates.

Results: A total of 41 (27.3\%) of 150 patients were MRSA carriers. The mean age of participants MRSA carriers was $35.27 \pm 20.40$ years old. The highest prevalence rate of nasal colonization with MRSA was in males (27.94\%) than females (26.82\%). In logistic regression analysis, no significant differences was detected between MRSA carriage and the associated risk factors including age [OR: 0.99 (95\% CI: 0.97- 1.01); $P=0.45$ ], gender [OR: 1.05 (95\% CI: 0.51- 2.17); $P=0.87$ ] and medical comorbidities [OR: 1.11 (95\% CI: 0.42- 2.92); $P=0.82]$.

Conclusions: Age, gender and medical comorbidities were not associated common risk factors for nasal colonization of MRSA in preoperative patients. This study should be considered preliminary and studies with larger sample sizes and with using advance molecular tools are needed in the future.
\end{abstract}

KEYWORDS: Risk factors, MRSA, Nasal Colonization, Preoperative patients, Duhok.

\section{BACKGROUND}

Staphylococcus aureus (S. aureus) is one of the most commonly isolated infectious Staphylococcus species and one of the main human bacterial pathogens (Wertheim et al., 2005). It can predispose a wide range of minor to life-threatening diseases including osteomyelitis, pneumonia, endocarditis, toxic shock syndrome (TSS) and Skin and soft tissue infections (SSTIs) (Kong et al., 2016). The main natural reservoirs are the asymptomatic human carriers and the main site of colonization is the frontal part of the nasal mucosal. Permanent nasal colonization can be found in up to $30 \%$ of the human population and is considered as the major predisposing aspect in the pathogenesis of disease (Sakr et al., 2018).

Overuse and misuse of antibiotics have led to increased levels of antibiotics-resistance. Methicillin was invented for the treatment of penicillin-resistant $S$. aureus. However, MRSA strains started to emerged and at the beginning such strains were considered a challenge in hospitals and health care units. Then, MRSA turned into a public-health problem affecting healthy individuals and became the most frequent cause of skin and soft-tissue infections in communities (Zetola et al., 2005, Zafar et al., 2007). Until recently, MRSA infections were confined to patients with established risk factors within the system of healthcare service and considered hospital acquired infection MRSA (Green et al.,2012). Thereafter, communityacquired MRSA (CA-MRSA) appeared in healthy individuals within society settings without established risk factors (Wang et al., 2009). The vast majority of MRSA strains carry mecA gene which is held by staphylococcal cassette chromosome mec (SCCmec) type (Ahmad et al., 2009). Conversely, community-associated (MRSA-CA) and health care-associated MRSA (HA-MRSA) are diverse in several genetic and phenotypic characteristics, with CA-MRSA being more virulent as they usually contain Panton-Valentine Leukocidin (PVL) (Chen et al., 2012). PVL is a cytotoxin that causes leukocyte destruction and tissue necrosis. It has been previously reported that PVL toxin is commonly associated with CA-MRSA (Gillet et al., 2002)

MRSA colonization appears to play a key role in the acquisition of infection, therefore the identification of colonization risk factors is important for the prevention and control of bacterial infection (Sganga et al., 2017). The most common reported associated risk factors for MRSA colonization are nursing home residence, hospitalization history within past 12 months, administration of antibiotic in the previous 3 months, previous MRSA infection, chronic skin disease, chronic hemodialysis, immunosuppression and presence of indwelling medical device (Torres et al., 2012).

\footnotetext{
* Corresponding author

This is an open access under a CC BY-NC-SA 4.0 license (https://creativecommons.org/licenses/by-nc-sa/4.0/)
} 
Among the postoperative complications; surgical site infections (SSI) are a major prevalent and they can arise as a consequence of several perioperative factors (Sakr et al., 2018). It has been reported previously, that MRSA remains a common and serious causative bacterial pathogen for SSIs (Sganga et al., 2017). MRSA colonization is associated with a fourfold increase in infection rate compared to methicillin-sensitive $S$. aureus (MSSA). Since nasal colonization of MRSA is associated with an increased infection risk of postoperative patients (Choi et al., 2019), therefore, studies on the identification of colonization risk factors are critical to help in planning for preventive strategies and control of the MRSArelated infections.

This study aimed to investigate the most common associated risk factors with MRSA nasal colonization among preoperative patients in Azadi Teaching Hospital - Duhok Province, Kurdistan Region - Iraq.

\section{METHODS}

\subsection{Study Design and Data Collection}

A cross-sectional study was carried out at Azadi Teaching Hospital - Duhok province, Kurdistan Region, Iraq between April 2017 and April 2018 recruiting preoperative patients. A total of 150 patients who were scheduled for various elective surgeries were recruited in the present study. The participants were interviewed and information on risk factors associated with MRSA colonization was acquired by using a standardized questionnaire. Samples were obtained by inserting a moistened swab with sterile saline into both anterior nares to a depth for about $1 \mathrm{~cm}$ and then rotated gently for 3 seconds and directly transported for specimens processing. The collected data in the present study included age, gender, and medical comorbidities. The interview was completed by obtaining nasal swabs from enrolled subjects.

\subsection{Identification of MRSA and Antimicrobial Susceptibility Testing}

The collected swabs were inoculated into mannitol salt agar immediately after reaching the lab and then incubated at $35^{\circ} \mathrm{C}$ for 48 hs. S. aureus strains were identified based on mannitol fermentation, morphological characteristics, Gram stain, coagulase and catalase test. Antimicrobial susceptibility test to oxacillin $(6 \mu \mathrm{g} / \mathrm{ml})$ was performed on Mueller Hinton Agar (Oxoid Limited, UK) using disk diffusion by the Kirby Bauer methods according to the guidelines of the Clinical Laboratory Standards Institute (CLSI) to identify MRSA strains

\subsection{Ethics consideration}

The study protocol and informed agreement were accepted by the Research Ethics committee in the University of Duhok, College of Medicine - Kurdistan Region-Iraq. Informed agreement was acquired from al recruited subjects and for participants less than 18 years old; informed consent was acquired from legal guardians.

\subsection{Statistics}

Statistical analysis of findings was performed using Minitab software version 17.0 (Minitab, Inc., Pennsylvania 16801, USA). Continuous data were calculated as means \pm standard deviations (SD) and frequencies were identified for categorical data using descriptive analysis. Logistic regression statistical analysis was applied to evaluate the association of risk factors with MRSA nasal colonization carriage. The strength of association was described according to the adjusted odds ratio $(\mathrm{OR})$ and $95 \%$ confidence interval $(95 \% \mathrm{CI}) . P$-value of $<0.05$ was regarded as statistically significant differences.

\section{RESULTS}

A total of 150 participants were enrolled during the study period. Of these, $68(45.3 \%)$ were males and $82(54.7 \%)$ were females. The age of recruited subjects ranged from 2 to 84 years old, with an average mean of $36.99 \pm 17.23$ years. In this study, $41 / 150$ were MRSA carriers giving a prevalence rate of $27.3 \%$. The average age of MRSA carriers was $35.27 \pm 20.40$ years. The gender distribution of MRSA carriage for males and females was 19/68 (27.94\%) and 22/82 (26.82\%), respectively. Logistic regression statistical models were applied to recognize predictive risk factors of MRSA colonization. Of the studied risk factors, age [OR: 0.99 (95\% CI: $0.97-1.01), P=0.45$ ], gender [OR: 1.05 (95\% CI: $0.51-2.17), P=0.87$ ] and medical comorbidities [OR: 1.11 (95\% CI: $0.42-2.92), P=0.82$ ] were not significantly associated with MRSA colonization.

\section{DISCUSSION}

S. aureus infections are of great importance because of invasiveness, toxin-mediated virulence, and resistance to antimicrobial agents (Qiu et al., 2010). MRSA is one of the main multi-drug-resistant organisms (MDROs) and there has been an increase in its incidence over the past decade, making a public health issue worldwide (Peters et al., 2019). Furthermore, MRSA is a growing concern in both hospital and community setting since it has increased the disease burden due to prolonged hospital stays, increased medical costs and high mortality (Kadariya et al., 2019). Numerous researches verified that $S$. aureus nasal colonization including MRSA is an important independent infection risk factor (Datta et al., 2014, Wertheim et al., 2005). A large percentage of MRSA infections comes from endogenous origin and are induced by the same strain that generally colonizes the nasal mucosa (von Eiff et al., 2001)

Globally, there is a statistically significant difference in the nasal carriage rate of MRSA as it varies geographically. The prevalence rate of MRSA colonization in healthcare workers in Germany, Turkey, China, Argentina, Egypt and Iran was 1.6\% (Peters et al., 2017), 2.9\% (Oguzkaya-Artan et al., 2015), 4.1\% (Kong et al., 2018), 6.3\% (Boncompain et al., 2017), 17.8\% (Hashim et al., 2018) and 22.5\% (Pourramezan et al., 2019), respectively. These variations are likely due to differences in the usage of antimicrobial and infection control measures (Diekema et al., 2001). In Iraq, several studies have reported nasal carriage rate of MRSA colonization in society and hospital varying from $4.2 \%$ to $10 \%$ (Assafi et al., 2015, Hussein et al., 2015, Hussein et al., 2019) and 50.4\% to $61 \%$ (Hussein, 2016, Hussein et al., 2017, Hussein et al., 2019), respectively. These reports indicated high rates of MRSA colonization. Therefore, an exploration of the colonization risk factors is very crucial. In the current study, we evaluated the association of MRSA colonization with each of age, gender and medical comorbidities. We found that there was no statistically significant association between age and MRSA carriage and our findings were in agreement with several other studies, worldwide (Berrocal et al., 2012, Altınbas et al., 2013). Our results contradict a previous study conducted in Iraq as well as the majority of reports elsewhere where they found a rise in the nasal colonization rate of MRSA with advancing age (Kuehnert et al., 2006, Hussein et al., 2017). Elder are expected to be a higher risk infection category towards MRSA because they are likely to have frequent hospital visits due to chronic illnesses and age-related issues (Sfeir et al., 2014). However, other studies showed that younger people have an increased risk for MRSA colonization (Munckhof et al., 2009, Halablab et al., 2010). Therefore, the association between age and MRSA nasal colonization remains controversial; further studies using advance molecular tools are required to discover this. 
In the present study, gender was not a significant risk factor association for MRSA carrier, resulting that both sexes had a roughly similar infection rate of MRSA carriage $(27.94 \%$ for male and $26.82 \%$ for female). These results are consistent with the data of the previous study conducted in Duhok province, Iraq (Hussein et al., 2017). Similar findings were also detected in a study carried out in Georgia (Hidron et al., 2005). However, several of the previous studies reported that male gender is a major associated risk factor for the nasal colonization for MRSA (Munckhof et al., 2009, Halablab et al., 2010). The male predominance in MRSA carriage could be due to gender differences in behavior and hand-hygiene practice with males being less compliant (Sharir et al., 2001). Furthermore, several researches have demonstrated that female hormones particularly estrogens have immune-modulating roles, and that may attribute to lower colonization and infection rates in females (Fish, 2008, Humphreys et al., 2015).

In a previous study conducted in Taiwan among community individuals, presence of chronic medical diseases was not associated with MRSA colonization (Wang et al., 2009). In agreement with prior studies in Turkey (Altıbas et al., 2013), Lebanon (Sfeir et al., 2014) and Korea (Choi et al., 2019), our results found no significant differences between colonization MRSA carriage and medical comorbidities. This contrasts with other studies where they reported medical comorbidities as a significant risk factor for MRSA colonization (Haddadin et al., 2002, Halablab et al., 2010). A further research with a larger population sample from different provinces in Iraq is required to explore such relationships.

To conclude, age, gender and medical comorbidities were not recorded as a major risk factors for nasal colonization with MRSA in preoperative patients. The present study should be considered preliminary and studies with larger sample sizes are needed in the future. Furthermore, more risk factors such as family socioeconomic status, history of previous antibiotic usage, previous MRSA infection and surgeries should be evaluated.

\section{REFERENCES}

AHMAD, N., RUZAN, I. N., ABD GHANI, M. K., HUSSIN, A., NAWI, S., AZIZ, M. N., MANING, N. \& EOW, V. L. K. 2009. Characteristics of community- and hospital-acquired meticillin-resistant Staphylococcus aureus strains carrying SCCmec type IV isolated in Malaysia. J Med Microbiol, 58, 1213-1218

ALTiNBAS, A., SHORBAGI, A., ASCiOGLU, S., ZARAKOLU, P. \& CETINKAYA-SARDAN, Y. 2013. Risk Factors for Intensive Care Unit Acquired Nasal Colonization of MRSA and Its Impact on MRSA Infection. Journal of Clinical Laboratory Analysis, 27, 412-417.

ASSAFI, M., MOHAMMED, Q. \& HUSSEIN, N. 2015. Nasal Carriage Rates of Staphylococcus aureus and CAMethicillin Resistant Staphylococcus aureus among University Students. Journal of Microbiology Research, 5, 123-127.

BERROCAL, M. H., LÓPEZ, V., ACABÁ, L. A. \& ACABÁ, A. 2012. Prevalence and risk factors of methicillin-resistant Staphylococcus aureus nasal carriage among ophthalmology outpatients in Puerto Rico. Investigative Ophthalmology \& Visual Science, 53, 6262-6262.

BONCOMPAIN, C. A., SUÁREZ, C. A. \& MORBIDONI, H. R. 2017. Staphylococcus aureus nasal carriage in health care workers: First report from a major public hospital in Argentina. Revista Argentina de Microbiología, 49, 125 131

CHEN, C.-S., CHEN, C.-Y. \& HUANG, Y.-C. 2012. Nasal carriage rate and molecular epidemiology of methicillin-resistant Staphylococcus aureus among medical students at a Taiwanese university. International Journal of Infectious Diseases, 16, e799-e803.

CHOI, S. W., LEE, J. C., KIM, J., KIM, J. E., BAEK, M. J., PARK, S Y., PARK, S. \& SHIN, B. J. 2019. Prevalence and Risk
Factors for Positive Nasal Methicillin-Resistant Staphylococcus aureus Carriage Among Orthopedic Patients in Korea. J Clin Med, 8.

DATTA, R., SHAH, A., HUANG, S. S., CUI, E., NGUYEN, V., WELBOURNE, S. J., QUAN, K. A. \& THRUPP, L. 2014. High nasal burden of methicillin-resistant Staphylococcus aureus increases risk of invasive disease. Journal of clinical microbiology, 52, 312-314.

DIEKEMA, D. J., PFALLER, M. A., SCHMITZ, F. J., SMAYEVSKY, J., BELL, J., JONES, R. N. \& BEACH, M. 2001. Survey of infections due to Staphylococcus species: frequency of occurrence and antimicrobial susceptibility of isolates collected in the United States, Canada, Latin America, Europe, and the Western Pacific region for the SENTRY Antimicrobial Surveillance Program, 1997-1999. Clin Infect Dis, 32 Suppl 2, S114-32.

FISH, E. N. 2008. The X-files in immunity: sex-based differences predispose immune responses. Nat Rev Immunol, 8, 737-44.

GILLET, Y., ISSARTEL, B., VANHEMS, P., FOURNET, J. C. LINA, G., BES, M., VANDENESCH, F., PIÉMONT, Y., BROUSSE, N., FLORET, D. \& ETIENNE, J. 2002. Association between Staphylococcus aureus strains carrying gene for Panton-Valentine leukocidin and highly lethal necrotising pneumonia in young immunocompetent patients. Lancet, 359, 753-9.

HADDADIN, A. S., FAPPIANO, S. A. \& LIPSETT, P. A. 2002. Methicillin resistant Staphylococcus aureus (MRSA) in the intensive care unit. Postgrad Med J, 78, 385-92.

HALABLAB, M. A., HIJAZI, S. M., FAWZI, M. A. \& ARAJ, G. F. 2010. Staphylococcus aureus nasal carriage rate and associated risk factors in individuals in the community. Epidemiol Infect, 138, 702-6.

HASHIM, A. E., ALI, A., ELMOLA, K., AMEEN, M., AWDALLA, H., EL HADY, A. \& EL RAEY, F. 2018. Nasal colonization of methicillin-resistant $<i>$ Staphylococcus aureus $</ \mathrm{i}>$ among medical residents in Al-Azhar University Hospital, Damietta branch. Al-Azhar Assiut Medical Journal, 16, 87-95.

HIDRON, A. I., KOURBATOVA, E. V., HALVOSA, J. S., TERRELL, B. J., MCDOUGAL, L. K., TENOVER, F. C., BLUMBERG, H. M. \& KING, M. D. 2005. Risk Factors for Colonization with Methicillin-Resistant Staphylococcus aureus (MRSA) in Patients Admitted to an Urban Hospital: Emergence of Community-Associated MRSA Nasal Carriage. Clinical Infectious Diseases, 41, 159-166.

HUMPHREYS, H., FITZPATICK, F. \& HARVEY, B. J. 2015. Gender differences in rates of carriage and bloodstream infection caused by methicillin-resistant Staphylococcus aureus: are they real, do they matter and why? Clin Infect Dis, 61, 170814.

HUSSEIN, N. 2016. Prevalent Genotypes of Staphylococcus aureus Strains Isolated From Healthcare Workers in Duhok City, Kurdistan Region, Iraq. International Journal of Infection, 3.

HUSSEIN, N., SALIH, R. \& RASHEED, N. 2019. Prevalence of Methicillin-Resistant Staphylococcus aureus in Hospitals and Community in Duhok, Kurdistan Region of Iraq. International Journal of Infection, In Press.

HUSSEIN, N. R., ASSAFI, M. S. \& IJAZ, T. 2017. Methicillinresistant Staphylococcus aureus nasal colonisation amongst healthcare workers in Kurdistan Region, Iraq. Journal of Global Antimicrobial Resistance, 9, 78-81.

HUSSEIN, N. R., BASHARAT, Z., MUHAMMED, A. H. \& ALDABBAGH, S. A. 2015. Comparative evaluation of MRSA nasal colonization epidemiology in the urban and rural secondary school community of Kurdistan, Iraq. PLoS One, $10, \mathrm{e} 0124920$.

KADARIYA, J., THAPALIYA, D., BHATTA, S., MAHATARA, R. L., BEMPAH, S., DHAKAL, N. \& SMITH, T. C. 2019. Multidrug-resistant Staphylococcus aureus Colonization in Healthy Adults Is more Common in Bhutanese Refugees in Nepal than Those Resettled in Ohio. BioMed research international, 2019, 5739247-5739247.

KONG, E. F., JOHNSON, J. K. \& JABRA-RIZK, M. A. 2016 Community-Associated Methicillin-Resistant Staphylococcus aureus: An Enemy amidst Us. PLoS Pathog, 12, e1005837.

KONG, Y., YE, J., ZHOU, W., JIANG, Y., LIN, H., ZHANG, X., QIAN, J., ZHANG, Y., GE, H. \& LI, Y. 2018. Prevalence 
of methicillin-resistant Staphylococcus aureus colonisation among healthcare workers at a tertiary care hospital in southeastern China. Journal of Global Antimicrobial Resistance, 15, 256-261.

KUEHNERT, M. J., KRUSZON-MORAN, D., HILL, H. A., MCQUILLAN, G., MCALLISTER, S. K., FOSHEIM, G., MCDOUGAL, L. K., CHAITRAM, J., JENSEN, B., FRIDKIN, S. K., KILLGORE, G. \& TENOVER, F. C. 2006. Prevalence of Staphylococcus aureus Nasal Colonization in the United States, 2001-2002. The Journal of Infectious Diseases, 193, 172-179.

MUNCKHOF, W. J., NIMMO, G. R., SCHOONEVELDT, J. M., SCHLEBUSCH, S., STEPHENS, A. J., WILLIAMS, G., HUYGENS, F. \& GIFFARD, P. 2009. Nasal carriage of Staphylococcus aureus, including community-associated methicillin-resistant strains, in Queensland adults. Clin Microbiol Infect, 15, 149-55.

OGUZKAYA-ARTAN, M., BAYKAN, Z., ARTAN, C. \& AVSAROGULLARI, L. 2015. Prevalence and risk factors for methicillin resistant Staphylococcus aureus carriage among emergency department workers and bacterial contamination on touch surfaces in Erciyes University Hospital, Kayseri, Turkey. African health sciences, 15, 1289-1294.

PETERS, C., DULON, M., KLEINMÜLLER, O., NIENHAUS, A. \& SCHABLON, A. 2017. MRSA Prevalence and Risk Factors among Health Personnel and Residents in Nursing Homes in Hamburg, Germany - A Cross-Sectional Study. PloS one, 12, e0169425-e0169425.

PETERS, C., DULON, M., NIENHAUS, A. \& SCHABLON, A. 2019. Occupational Infection Risk with Multidrug-Resistant Organisms in Health Personnel-A Systematic Review. International journal of environmental research and public health, 16, 1983.

POURRAMEZAN, N., OHADIAN MOGHADAM, S. \& POURMAND, M. R. 2019. Methicillin-resistant Staphylococcus aureus tracking spread among health-care workers and hospitalized patients in critical wards at a university hospital, Tehran, Iran. New Microbes and New Infections, 27, 29-35.

QIU, J., FENG, H., LU, J., XIANG, H., WANG, D., DONG, J. WANG, J., WANG, X., LIU, J. \& DENG, X. 2010. Eugenol Reduces the Expression of Virulence-Related Exoproteins in $<\mathrm{em}>$ Staphylococcus aureus $</ \mathrm{em}>$. Applied and Environmental Microbiology, 76, 5846-5851.

SAKR, A., BRÉGEON, F., MÈGE, J.-L., ROLAIN, J.-M. \& BLIN, O. 2018. Staphylococcus aureus Nasal Colonization: An Update on Mechanisms, Epidemiology, Risk Factors, and
Subsequent Infections. Frontiers in microbiology, 9, 24192419.

SFEIR, M., OBEID, Y., EID, C., SALIBY, M., FARRA, A., FARHAT, H. \& MOKHBAT, J. E. 2014. Prevalence of Staphylococcus aureus methicillin-sensitive and methicillin-resistant nasal and pharyngeal colonization in outpatients in Lebanon. Am J Infect Control, 42, 160-3.

SGANGA, G., TASCINI, C., SOZIO, E. \& COLIZZA, S. 2017. Early recognition of methicillin-resistant Staphylococcus aureus surgical site infections using risk and protective factors identified by a group of Italian surgeons through Delphi method. World journal of emergency surgery : WJES, 12 , 25-25.

SHARIR, R., TEITLER, N., LAVI, I. \& RAZ, R. 2001. High-level handwashing compliance in a community teaching hospital: a challenge that can be met! J Hosp Infect, 49, 55-8.

TORRES, K., SAMPATHKUMAR, P. \& SISKA, M. 2012. Risk Factor Score to Predict MRSA Colonization at Hospital Admission. American Journal of Infection Control, 40, e185.

VON EIFF, C., BECKER, K., MACHKA, K., STAMMER, H. \& PETERS, G. 2001. Nasal carriage as a source of Staphylococcus aureus bacteremia. Study Group. $N$ Engl J Med, 344, 11-6.

WANG, J.-T., LIAO, C.-H., FANG, C.-T., CHIE, W.-C., LAI, M.-S., LAUDERDALE, T.-L., LEE, W.-S., HUANG, J.-H. \& CHANG, S.-C. 2009. Prevalence of and Risk Factors for Colonization by Methicillin-Resistant $<$ em $>$ Staphylococcus aureus $</$ em $>$ among Adults in Community Settings in Taiwan. Journal of Clinical Microbiology, 47, 2957-2963.

WERTHEIM, H. F., MELLES, D. C., VOS, M. C., VAN LEEUWEN, W., VAN BELKUM, A., VERBRUGH, H. A. \& NOUWEN, J. L. 2005. The role of nasal carriage in Staphylococcus aureus infections. Lancet Infect Dis, 5, 75162.

ZAFAR, U., JOHNSON, L. B., HANNA, M., RIEDERER, K., SHARMA, M., FAKIH, M. G., THIRUMOORTHI, M. C., FARJO, R. \& KHATIB, R. 2007. Prevalence of nasal colonization among patients with community-associated methicillin-resistant Staphylococcus aureus infection and their household contacts. Infect Control Hosp Epidemiol, 28, 966-9.

ZETOLA, N., FRANCIS, J. S., NUERMBERGER, E. L. \& BISHAI, W. R. 2005. Community-acquired meticillin-resistant Staphylococcus aureus: an emerging threat. The Lancet. Infectious diseases, 5, 275-286. 